\title{
PHẪU THUẬT THÀNH CÔNG SỦA CHŨ̃A HOÀn TOÀN THÂN CHUNG ĐộNG MẠCH TYPE I Ở BỆNH NHÂN 16 TUỔI KHÔNG CÓ YẾU TỐ BẢO VỆ PHỔI
}

\author{
Bùi Minh Thành*, Phan Quan Thuận*, Nguyê̂n Anh Düng*, Khánh Nguyễn**
}

\section{TỒNG QUAN}

Thân chung động mạch (TA) là một bất thường bẩm sinh hiếm gặp với sự cấu thành bình thường của tầng nhĩ và tương hợp nhĩ thất phù hợp nhưng chỉ có một thân chung động mạch cấp máu cho động mạch vành, động mạch phổi và động mạch hệ thống [11]. Bất thường bẩm sinh này chiếm $1,2 \%$ tất cả các dị tật tim bẩm sinh [13]. TA được phân loại theo hai hệ thống, chủ yếu theo phân loại của tác giả

Collett - Edwards và Van Praagh, dựa trên nguyên ủy xuất phát của động mạch phổi (ĐMP) [13]. Ở đây, chúng tôi xin trình bày cách phân loại của tác giả Collett - Edwards. Theo Collett - Edwards thì type I có một thân chung ĐMP xuất phát

nguyên ủy từ động mạch chủ (ĐMC) và chia thành hai nhánh động mạch phổi phải và trái; trong khi đó type II không tồn tại rõ ràng thân chung ĐMP, ĐMP phải và trái xuất phát cùng nguyên ủy từ TA; type III không có thân chung ĐMP, ĐMP phài và trái xuất phát từ hai nguyên ủy riêng biệt trên TA; đối với type IV không tồn tại cả thân chung ĐMP và các nhánh ĐMP phổi được cấp máu từ các nhánh tuần hoàn bang hệ chủ phổi, loại này cũng được gọi là thiểu sản phồi kèm thông liên thất [13]. Trước kỷ nguyên phẫu thuật tim gần $80 \%$ trẻ bị bệnh tim bẩm sinh này tử vong trong năm đầu tiên của cuộc sống [3,11]. Nếu trẻ được sữa chữa sớm lúc tuổi nhũ nhi thì, kết cục được báo cáo vào năm 1997, tỷ lệ sống sau 5 năm là $90 \%$, sau 10 năm là $95 \%$, sau 15 năm là $85 \%$ [13]. Những số liệu trên cho thấy việc trẻ không được điều trị mà sống tới lúc thiếu niên là rất hiếm gặp và số bệnh nhân sống sót này sẽ phát triển bệnh mạch máu phổi không hồi phục [11]. Tỷ lệ sống còn của bệnh nhân thân chung động mạch type I tới tuổi thiếu niên hoặc trưởng thành không được thống kê đày đủ, chỉ có báo cáo rất ít qua các trường hợp đơn độc [11]. Các trường hợp không đủ điều kiện để sữa chữa triệt để lần đầu, có thể được trì hoãn bằng banding động mạch phổi, thường thực hiện ở các bệnh nhân có biến chứng bệnh mạch máu phổi và thường gặp ở bệnh thân chung động mạch sống sót trên 1 tuổi [11]. Vì thế việc phẫu thuật sữa chữa hoàn toàn cho bệnh nhân thân chung động mạch type I còn sống sót đến tuổi thiếu niên mà chưa trãi qua bất kỳ can thiệp nào trước đó là cực kỳ hiếm, chưa tìm thấy báo cáo trong y văn. Do vậy, chúng tôi báo cáo một trường hợp phẫu thuật sửa chữa hoàn toàn bệnh thân chung động mạch vào năm 16 tuổi, không trải qua bất kì can thiệp nào trước đó.

\section{BÁO CÁO TRƯờnG HợP}

Bệnh nhân nam 16 tuổi, được chẩn đoán bệnh thân chung động mạch (TA) type I vào thời nhũ nhi. Vì điều kiện kinh tế nên không được phẫu thuật và được điều trị nội khoa. Bệnh nhân chậm tăng cân, hoạt động thể lực rất hạn chế do thường xuyên mệt và khó thở khi gắng sức nhẹ. Cho đến khi gia đình có khả năng tài chính cho việc phẫu thuật, thì các trung tâm tim mạch đã từ chối mổ cho bệnh nhân.

Bệnh nhân nhập viện trong tình trạng suy tim nặng NYHA III. Khám lâm sàng ghi nhận: thể trạng gầy, suy dinh dưỡng, tĩnh mạch cổ nổi, âm thổi tâm thu 4/6 ở mỏm tim, độ bảo hoà oxy khoảng 90-94\% với khí phòng. Sau khi được hội

* Khoa PT Tim Bệnh viện Nhân Dân Gia Định

** Mount Sinai Hospital, New York.

Ngưòi chịu trách nhiệm khoa học: Bùi Minh Thành

Ngày nhận bài: 02/08/2020 - Ngày Cho Phép Đăng: 04/09/2020

Phản Biện Khoa học: PGS.TS. Đặng Ngoc Hùng PGS.TS. Nguyến Hũu Ước 
chẩn và tư vấn phẫu thuật, bố mẹ không đồng ý mổ, bệnh nhân được xuất viện tiếp tục điều trị nội khoa. Tuy nhiên, hai tháng sau đó bệnh nhân tái nhập viện vì triệu chứng suy tim nặng nề hơn, với diễn tiến tăng dần NT-ProBNP lần lượt là: $460.2 \mathrm{pg} /, 1310 \mathrm{pg} / \mathrm{mL}$ và $1642 \mathrm{pg} / \mathrm{mL}$

X-quang phổi trước mổ với bóng tim to, dấu comma ở rốn phổi trái, lớn các buồng tim, thân chung to. (hình 1) tương ứng 07/2017, 9/2017 và 1/2018. Siêu âm bụng ghi nhận tĩnh mạch gan giữa giãn $11 \mathrm{~mm}$, theo dõi bệnh lý gan tim, nhưng sinh hoá máu ghi nhận chức năng gan và thận trong giới hạn bình thường. Điện tâm đồ ghi nhận giãn lớn thất phải.

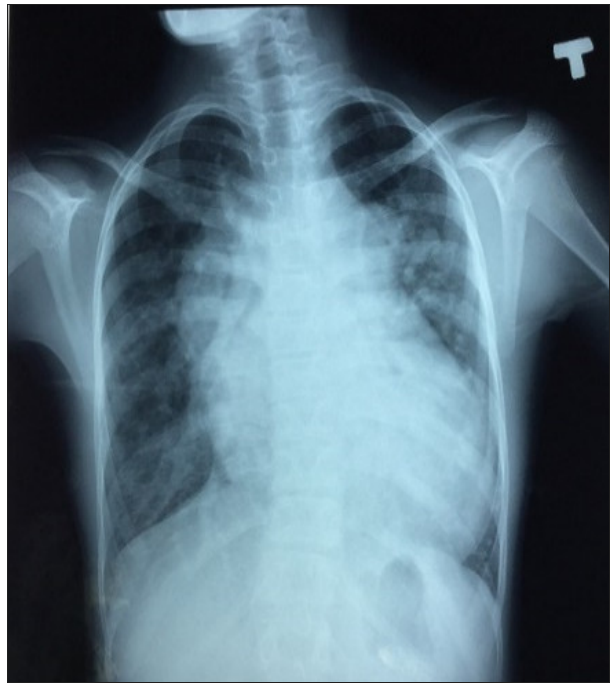

Hình 1. X-Quang trước mổ

Siêu âm tim ghi nhận bệnh thân chung động mạch type I với: thân chung cưỡi ngựa trên vách liên thất, có đường kính $45 \mathrm{~mm}, 1$ bộ máy van với van 3 mảnh, thông liên thất dưới thân chung $27 \mathrm{~mm}$, shunt trái phải, lưu lượng cao, chênh áp thất trái/ thất phải là $45 / 35 \mathrm{mmHg}$. Thân động mạch phổi xuất phát từ mặt trái thân chung, thân và các nhánh động mạch phổi dãn lớn, hợp lưu. Khoảng cách từ van động mạch chủ đến chỗ tách thân động mạch phổi là $31 \mathrm{~mm}$. Động mạch phổi có đường kính thân là $35 \mathrm{~mm}$, nhánh phải là $29 \mathrm{~mm}$, nhánh trái là $24 \mathrm{~mm}$. Động mạch chủ lên sau chỗ tách: thân $35 \mathrm{~mm}$, ngang $24 \mathrm{~mm}$, eo $18 \mathrm{~mm}$, chức năng tâm thu thất trái khoảng $71 \%$, hở van 3 lá 3/4 tăng áp phổi nặng với PAPs $=90 \mathrm{mmHg}$.

MSCT ghi nhận: tồn tại tĩnh mạch chủ trên bên trái đổ vào xoang vành, cuối cùng về nhĩ phải; đường kính buồng thất trái thì tâm trương là $53 \mathrm{~mm}$ và thì tâm thu là $42 \mathrm{~mm}$, đường kính buồng thất phải thì tâm trương là $22 \mathrm{~mm}$ và thì tâm thu là 

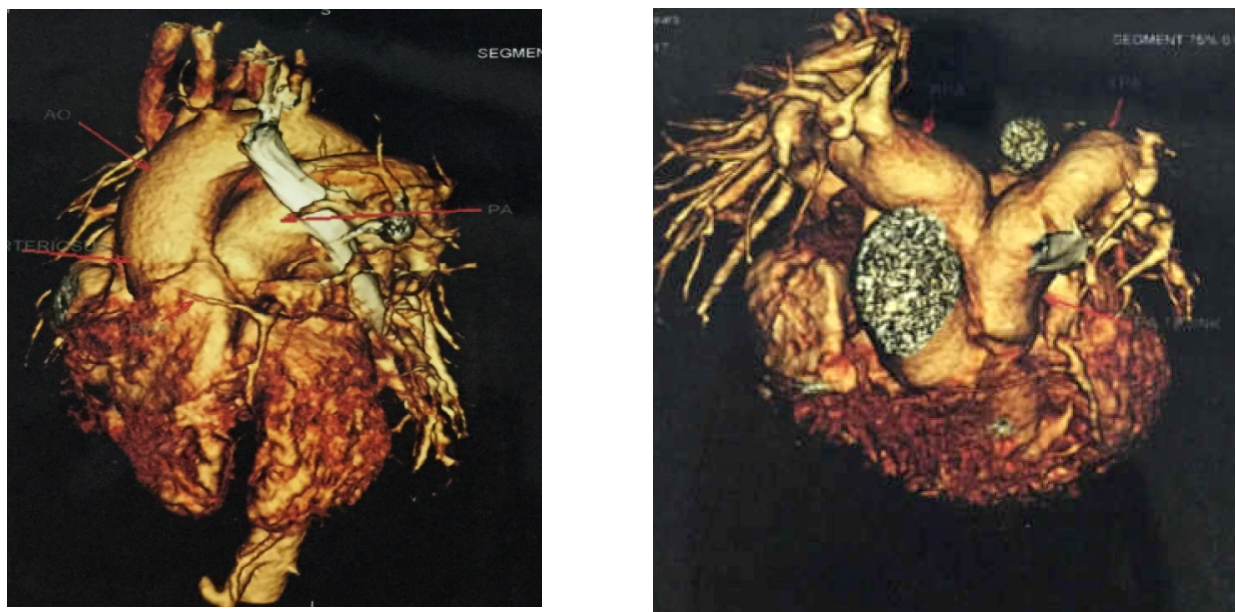

Hình 2. MSCT ngực dựng hình: Tim giãn lớn, thân chung động mạch chia thành động mạch chủ lên, thân động mạch phổi, thân động mạch vành $\mathrm{T}$.
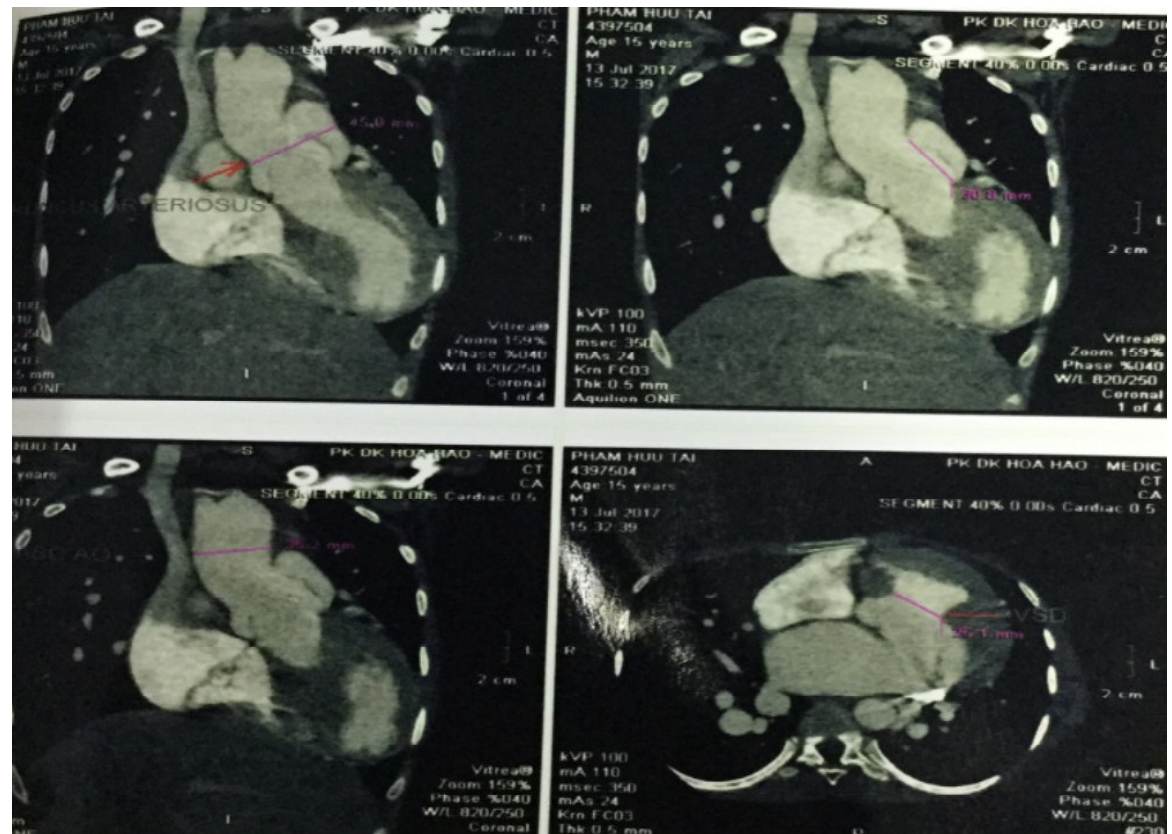

Hình 3. MSCT ngực: Thân chung $(\mathrm{d}=45 \mathrm{~mm})$. Thân động mạch phổi xuất phát từ mặt bên trái của thân chung $(\mathrm{d}=35 \mathrm{~mm})$; Động mạch chủ lên $(\mathrm{d}=35 \mathrm{~mm})$. Động mạch vành phải xuất phát từ $\mathrm{LAD}$ bắt chéo trước gốc thân chung

Kết quả thông tim: Áp lực động mạch phổi là $90 / 55 / 72 \mathrm{mmHg}$, áp lực động mạch chủ là $110 / 56 / 80 \mathrm{mmHg}$, áp lực nhĩ phải là $12 \mathrm{mmHg}$, áp lực mao mạch là $20 \mathrm{mmHg}$. Chụp mạch máu phổi ra tới 1/3 ngoài phế trường. $\mathrm{Qp} / \mathrm{Qs}=3.2$. Kháng lực mạch máu phổi là 7.48 Wood, tỉ lệ kháng lực mạch máu phổi trên kháng lực hệ thống là 0.24 .
Bệnh nhân được phẫu thuật sửa chữa hoàn toàn vào ngày $26 / 01 / 2018$ bằng đường mở ngực dọc giữa xương ức, tuần hoàn ngoài cơ thể và hạ thân nhiệt đến $28^{\circ} \mathrm{C}$. Bóc tách bộc lộ vị trí động mạch phổi trái và động mạch phổi phải. Tách thân động mạch phổi khỏi động mạch chủ. Tạo hình gốc và thân động mạch chủ lên bằng miếng vá nhân tạo Dacron. Mở phễu thất phải, Đóng lỗ 
thông liên thất ngay dưới thân chung động mạch có đường kính là $20 \mathrm{~mm}$ bằng miếng vá sinh học bằng màng ngoài tim bò. Tạo hình gốc thân, động mạch phổi và thiết lập đường thoát thất phải bằng ống Hancook có van sinh học số 22 từ vùng phễu thất phải đến chỗ hợp lưu hai nhánh động mạch phổi. Áp lực động mạch phổi sau khi tim đập lại bình thường là 53/29/44 mmHg, áp lực động mạch chủ là $83 / 45 / 58 \mathrm{mmHg}$. Cai dần và ngưng được tuần hoàn ngoài cơ thể. Thời gian tuần hoàn ngoài cơ thể là 189 phút, thời gian kẹp động mạch chủ là 171 phút.
Sau mổ, bệnh nhân được an thần sâu, thở máy để duy trì nồng độ oxy riêng phần trong máu động mạch (PaO2) trong khoảng 100-120mmHg, nồng độ cacbon dioxide $(\mathrm{PaCO} 2)$ riêng phần trong khoảng $35-45 \mathrm{mmHg}$, đồng thời truyền liên tục Milrinone kiểm soát về huyết động và theo dõi áp lực động mạch phổi thông qua siêu âm tim. Vấn đề chảy máu sau mổ được kiểm soát trong 8 giờ đầu, sau đó huyết động ổn định dần và chức năng tim cải thiện dần.
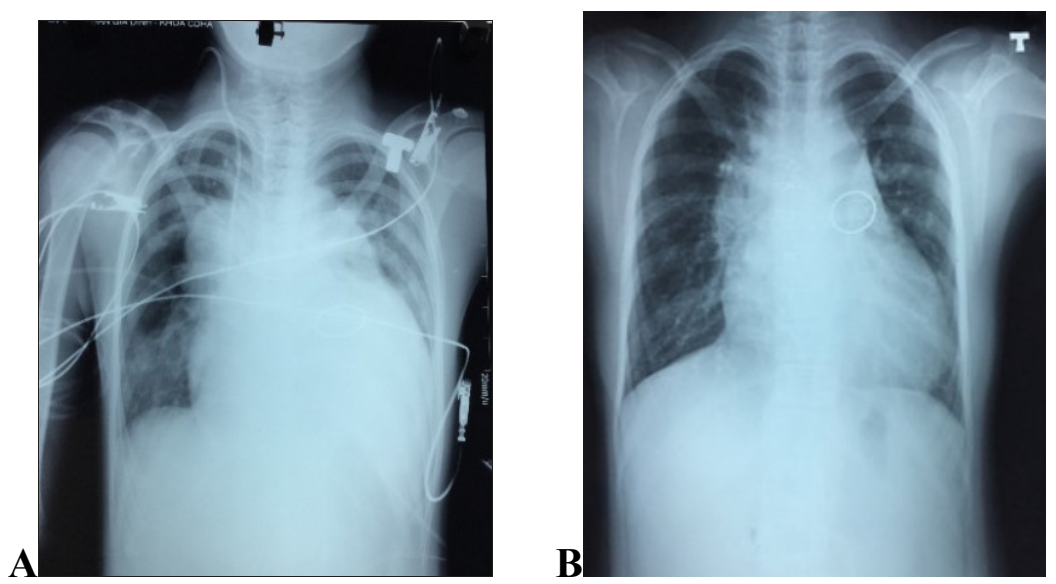

Hình 4. A: X-quang sau mổ, B: sau mổ 6 tháng.

Siêu âm tim kiểm tra lại sau mổ: $\mathrm{EF}=71 \%$, hở nhẹ van 3 lá $1 \frac{1}{4}, \mathrm{PAPs}=70 \mathrm{mmHg}$, vách liên thất kín, van thân chung làm van động mạch chủ không hẹp hở, xuất phát hoàn toàn từ thất trái, van động mạch phổi trong ống Handcook xuất phát từ thất phải.

Bệnh nhân được điều trị nội khoa suy tim tối ưu và tiếp tục duy trì bosentan khi xuất viện với phân độ suy tim NYHA III.

Sau 2 tháng: tái khám với triệu chứng suy tim được cải thiện trên lâm sàng với phân độ NYHA II.

Sau 6 tháng: theo dõi, bệnh nhân đến tái khám với phân độ suy tim NYHA I. Kết quả NT-Pro BNP xét nghiệm lại là $107 \mathrm{pg} / \mathrm{mL}$. Siêu âm tim lại sau 6 tháng ghi nhận vách liên thất kín, không ghi nhận luồng thông tồn lưu, hở van động mạch chủ nhẹ $1 / 4, \mathrm{~V} \max =1.2 \mathrm{~m} / \mathrm{s}$, chênh áp ngang van $5.8 / 3.1 \mathrm{mmHg}$, động mạch phổi đi ra hoàn toàn từ thất phải, $\mathrm{v}$ max $=1.6 \mathrm{~m} / \mathrm{s}$, chênh áp ngang van là 10/3.7mmHg. Hở van 3 lá 1.5/4. Tăng áp phổi nặng $P A P s=68 \mathrm{mmHg}$, chức năng tâm thu thất trái bảo tồn $\mathrm{EF}=68 \%$. 

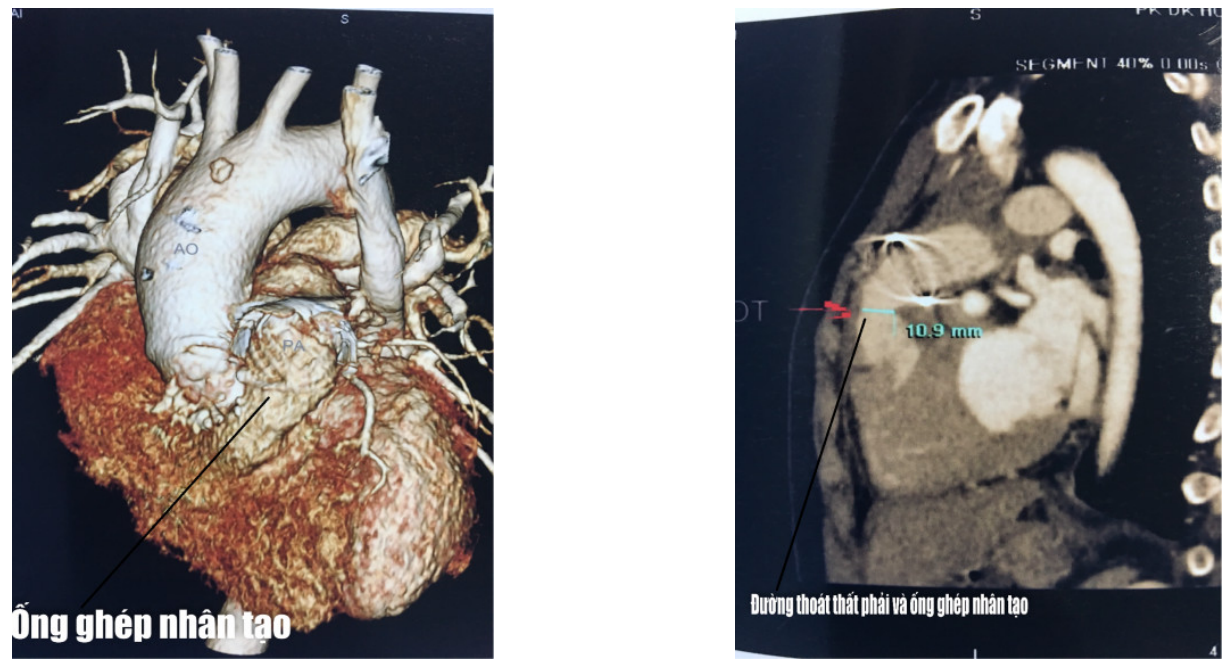

Hình 5. MSCT ngực 6 tháng sau mổ

\section{BÀN LUẬN}

Khi tiếp nhận điều trị bệnh nhân này, chúng tôi hiểu rằng có ba thách thức lớn rất khó vượt qua và được cân nhắc, bàn luận kỹ càng trước khi quyết định phẫu thuật: thứ nhất, bệnh lý mạch máu phổi do tăng áp lực phổi trường diễn và lâu ngày do không được bảo vệ phổi tự nhiên hay được can thiệp trước đó; thứ hai là, trong y văn chưa thấy ghi nhận trường hợp phẫu thuật thành công bệnh thân chung động mạch có tăng áp phổi nặng mà không hề có yếu tố bảo vệ phổi trước đó, và đây cũng chính là yếu tố cân nhắc nhiều lần vì chưa có kinh nghiệm trong trường hợp này, mặc khác việc cậy nhờ các thiết bị hỗ trợ thất trong trường hợp cứu vãn tình thế sau mổ lại càng không phù hợp, trong khi ghép bloc tim phổi là hoàn toàn không khả thi trong bối cảnh y tế trong nước; thứ ba là, khả năng suy thất phải nặng hoặc không hồi phục sau mổ do tăng áp phổi là rất cao, một vấn đề khó khăn lớn trong hồi sức sau mổ.

Theo y văn ghi nhận, khoảng 50\% bệnh nhân mắc bệnh lý thân chung động mạch tử vong trong vòng tháng đầu sau sinh, $70 \%$ tử vong trong 3 tháng và $85 \%$ tử vong trong 6 tháng. Chỉ khoảng $10 \%$ bệnh nhân sống sót đến tuổi thiếu niên, nhưng thường sẽ phát triển bệnh mạch máu phổi nặng gây nên tình trạng lâm sàng tím nặng dần và đi đến tử vong với sự phát triển của hội chứng Eisenmenger [9]. Điều này cho thấy bệnh nhân cần được phẫu thuật sửa chữa hoàn toàn vào thời kì sớm sau sinh, trước khi phát triển bệnh lý mạch máu phổi. Việc can thiệp trì hoãn là banding một hoặc cả hai động mạch phổi . Tuy nhiên, có nhiều vấn đề với việc banding động mạch phổi, như ở type 1 , band có thể di chuyển từ thân chung động mạch phổi đi vào 1 nhánh động mạch phổi gây tắc nghẽn 1 nhánh động mạch phổi và gây bệnh lý mạch máu phổi ở nhánh còn lại, hoặc thất bại với sự lớn lên của động mạch phổi gây biến dạng...[2][11]. Theo ghi nhận nhiều báo cáo, bệnh nhân thân chung động mạch sống sót sau 1 tuổi thông thường là, do đã được phẫu thuật banding động mạch phồi hoặc bản thân có hẹp phổi tự nhiên, không thường gặp bệnh nhân thân chung động mạch sống sót mà không có hẹp phổi và banding động mạch phổi. Tuy nhiên, cũng đã có báo cáo, 1 bệnh nhân nam với thân chung động mạch type A1 theo phân loại Van Praagh sống đến 11 tuổi và 1 phụ nữ với thân chung động mạch type 1 sống đến 33 tuổi nhưng không được can thiệp phẫu thuật [7]. Một trường hợp khác, một bệnh nhân nam bệnh thân chung động mạch type 1 sống tới 33 tuổi, đã được banding thân động mạch phổi lúc 4 tháng tuổi, nhưng gia đình chọn không điều trị phẫu thuật triệt để; kết quả là bệnh nhân nhập viện rất nhiểu lần vì suy tim và rồi bị viêm nội tâm mạc nhiễm khuẩn gây hở van thân chung, phải phẫu thuật triệt để và thành công [11]. Y văn đã ghi nhận 1 trường hợp bệnh nhân 
được phẫu thuật ở độ tuổi 28 , tuy nhiên đây là 1 trường hợp thân chung động mạch không điển hình và mạch máu phổi được bảo vệ đến tuổi trưởng thành nhờ vào sự hẹp tự nhiên ở gốc động mạch phổi [1]. Do vậy, việc phẫu thuật sữa chữa hoàn toàn bệnh thân chung động mạch mà không có yếu tố bảo vệ trước đó ở độ tuổi thiếu niên, theo chúng tôi là chưa được báo cáo cho đến thời điểm hiện tại. Việc thiếu các dữ kiện y văn tương tự khiến chúng tôi chấp nhận so sánh các biểu hiện lâm sàng và cận lâm sàng tương tự để khuyến khích điều trị mà không quan tâm tới bệnh nhân có điều trị trước đó hay không.

Tìm kiếm các dữ liệu trên y văn cho thấy, một báo cáo hàng loạt ca phẫu thuật sửa chữa ở trẻ lớn, và một vài trường hợp báo cáo ở người lớn. Điển hình, Marcelletti và cộng sự (cs), báo cáo một loạt 96 bệnh nhân phẫu thuật sửa chữa TA (73\% TA loại I, 18\% bị hẹp PA một phổi do tự nhiên hoặc banding) từ 1967 đến 1975, tî lệ tử vong sau mổ trong 30 ngày đối với trẻ sau 2 tuổi là $21 \%$ [11]. Trong khi đó Talwar và cộng sự báo cáo nhóm 9 bệnh nhi TA (7 trường hợp TA type I), trong đó 2 trẻ có hẹp động mạch phổi (PA) ,một tại gốc của thân $\mathrm{PA}$ và một ở gốc của động mạch phổi phải (RPA). Nhóm bệnh nhi này đã trải qua phẫu thuật sửa chữa ở độ tuổi trung bình là 3 ( 1 đến 12 tuổi), từ 2000 đến 2012, tỷ lệ tử vong bệnh viện là $22,2 \%$ [11]. Từ những phân tích trên y văn khiến chúng tôi rất cân nhắc kỹ càng trước quyết định can thiệp cho bệnh nhân ở độ tuổi 16 . Điều đáng suy nghĩ là chưa tìm được điểm tương đồng giữa các dữ kiện trên y văn, ở các trường hợp thành công, với bệnh cảnh lâm sàng của bệnh nhân mà chúng tôi đang hướng đến phẫu thuật sữa chữa hoàn toàn.

Sau khi thông tim đo kháng lực mạch máu phổi, chúng tôi đã cân nhắc giữa việc phẫu thuật hay không? Mối quan hệ giữa kháng lực mạch máu phổi (PVR) và nguy cơ phẫu thuật chỉ nghiên cứu ở bệnh nhân có đủ hai nhánh động mạch phổi phải và trái và nguy cơ phẫu thuật rất cao khi chî số PVR trên 8 [11]. Stegmann và cộng sự báo cáo 8 trường hợp sửa chữa TA loại I ở bệnh nhân có tuổi đời từ 2 tháng đến 4,5 năm (2 trong số đó đã có banding động mạch phổi trước) từ năm 1976 đến năm 1981, chỉ có một trẻ 3,5 tuổi chết sau phẫu thuật vì suy thất phải. Ở trẻ này, PVR đã tăng lên 13 Wu.m2 mặc dù đã banding PA [11.] Việc gia tăng trở kháng mạch máu phổi làm gia tăng nguy cơ tử vong sau mổ, khi kháng lực mạch máu phổi lớn hơn 5 và nhỏ hơn 8 thì tỉ lệ này đã tăng lên $20 \%$, và nếu lớn hơn 8 là 39\% [8]. Tác giả Wen Ruan và cs báo cáo kết quả phẫu thuật ở bệnh nhân nam 33 tuổi có PVR 10,2Wu.m2, cao hơn trị số RVP của bệnh nhân chúng tôi (bệnh nhân này đã được banding $\mathrm{PA}$ trước đó). Zhang và cộng sự báo cáo 12 bệnh nhân (83\% thân chung động mạch type 1) chỉ có 1 bệnh nhân bị hẹp động mạch phổi, tất cả bệnh nhân đã trải qua phẫu thuật sửa chữa $\mathrm{TA}$, tuổi trung bình 6,4 (từ 1,2 đến 19 tuổi), từ giữa năm 2006 đến năm 2010, không có trường hợp tử vong sớm hoặc phải mổ lai sau khi theo dõi trung hạn 2,4 năm (1,1 đến 5,3 năm), và tất cả các bệnh nhân nhân này đều có PVR dưới 8 [11]. Bệnh nhân của chúng tôi có kháng lực mạch máu phổi là 7.48 Wu.m2, đã tái nhập và xuất viện điều trị nội khoa suy tim tối ưu nhiều lần; Tuy nhiên, sau đó bệnh nhân suy tim nặng hơn nên phải tái nhập viện điều trị với NT-ProBNP tăng từ $460.2 \mathrm{pg} / \mathrm{mL}$ đến $1642 \mathrm{pg} / \mathrm{mL}$. Việc tiến triển nhanh suy tim trong một thời gian ngắn cùng với giá trị của $\mathrm{PVR}$ của bệnh nhân đã gần tiệm cận giới hạn cuối của nguy cơ cao về phẫu thuật mà còn có thể cứu vãng được, bằng không là không thể chỉ định phẫu thuật nữa, với một tiên lượng bất định cho một bệnh nhi mười lăm tuổi rưỡi. Diễn tiến bất lợi cho bệnh nhân đã đặt chúng tôi vào tình thế phải cân nhắc chọn lựa: hoặc là có thể hoặc không bao giờ, vào thời điểm nhất định đó. Cân nhắc đến quyết định phẫu thuật ngay khi còn kịp thời.

Việc kiểm soát cơn tăng áp phổi và suy tim phải sau mổ là một mục tiêu trị liệu quan trọng cần phải được lên kế hoạch và thực hiện ngay sau mổ. Một số báo cáo đề cập đến việc kiểm soát nguy cơ suy thất phải và cơn tăng áp phổi sau phẫu thuật thân chung động mạch bằng $\mathrm{NO}$ và/hay phối hợp van một chiều [6][4]. Việc đóng 
thông liên thất bằng miếng vá có van một chiều (unidirectional valve) cho phép luồng thông từ phải qua trái để giảm áp lực thất phải trong trường hợp gia tăng áp lực mạch máu phổi (type supra-systemic) sau mổ, hoặc để lại lỗ bầu dục với tác dụng tương tự [12][10]. Với kế hoạch điều trị dự phòng cơn tăng áp phổi bằng cách an thần sâu sau mổ, tiếp tục điều trị các thuốc giãn mạch phổi với thuốc uống qua sonde dạ dày, chẳng hạn như: bosentan, tadalafil ... phần nào khắc phục mặt hạn chế không có NO để điều trị khẩn cấp cơn tăng áp phổi sau mổ, điều này làm tăng nguy cơ tử vong sau mổ lên cao.

Sau phẫu thuật, triệu chứng suy tim của bệnh nhân cải thiện dần và đến 6 tháng sau mổ, bệnh nhân gần như có thể sinh hoạt bình thường. Do vậy, việc phẫu thuật sữa chữa hoàn toàn thân chung động mạch trong giai đoạn muộn (độ tuổi thiếu niên) là hoàn toàn khả thi và sự cải thiện về bệnh cảnh lâm sàng sau phẫu thuật thật là ngoài mong đợi.

\section{KẾT LUẬN}

Trưởng hợp lâm sàng này đã chứng minh việc phẫu thuật sửa chữa triệt để bệnh thân chung động mạch type 1 ở bệnh nhân thiếu niên mà không có can thiệp banding động mạch phổi trước đó hoặc có hẹp phổi tự nhiên là hoàn toàn khả thi trong điều kiện y tế ở Việt Nam. Kinh nghiệm này còn có thể đóng góp vào $\mathrm{y}$ văn trường hợp thân chung động mạch không có bảo vệ phổi và ở tuổi 16 được sữa chữa hoàn toàn thành công.

\section{TÀI LIỆU THAM KHẢO}

[1] Lopes L. M. et al. (2011), "Atypical truncus arteriosus operated at 28 years of age: importance of differential diagnosis", Arq Bras Cardiol. 97 (2), pp. e29-32.

[2] Bove E. L. et al. (1989), "Repair of truncus arteriosus in the neonate and young infant", Ann Thorac Surg. 47 (4), pp. 499-505; discussion 506.

[3] Brown J. W. et al. (2001), "Truncus arteriosus repair: outcomes, risk factors, reoperation and management", Eur J Cardiothorac Surg. 20 (2), pp. 221-227.
[4] Chiaw T. H. et al. (2007), "An adult with truncus arteriosus and unilateral pulmonary hypertension", Congenit Heart Dis. 2 (6), pp. 433-437.

[5] de Siena P. et al. (2011), "Common arterial trunk: review of surgical strategies and future research", Expert Rev Cardiovasc Ther. 9 (12), pp. 1527-1538.

[6] Guenther F. et al. (2009), "Cardiovascular flashlight. Persistent truncus arteriosus: a rare finding in adults", Eur Heart $J$. 30 (9), pp. 1154.

[7] Kharwar R. B. et al. (2014), "Persistent truncus arteriosus: a rare survival beyond the first decade", J Am Coll Cardiol. 63 (17), pp. 1807.

[8] Marcelletti C. et al. (1977), "Early and late results of surgical repair of truncus arteriosus", Circulation. 55 (4), pp. 636-641.

[9] Nicholas T. Kouchoukos M., Eugene H. Blackstone, MD, Frank L. Hanley, MD and James K. Kirklin, MD (2013), "Chapter 43: Truncus Arteriosus", Kirklin/Barratt-Boyes Cardiac Surgery, 4th Edition, Elsevier, pp. 16021625.

[10] Novick W. M. et al. (2005), "Flap valve double patch closure of ventricular septal defects in children with increased pulmonary vascular resistance", Ann Thorac Surg. 79 (1), pp. 21-28; discussion 21-28.

[11] Ruan W. et al. (2016), "Surgical correction of persistent truncus arteriosus on a 33year-old male with unilateral pulmonary hypertension from migration of pulmonary artery band", J Cardiothorac Surg. 11, pp. 39.

[12] Talwar S. et al. (2012), "Unidirectional valved patch closure of ventricular septal defects with severe pulmonary arterial hypertension", Interact Cardiovasc Thorac Surg. 14 (6), pp. 699-702.

[13] Indarini, Putu. (2016). TRUNCUS ARTERIOSUS TYPE I: A CASE REPORT. Indonesia Journal of Biomedical Science. 10. 5. 10.15562/ijbs.v10i1.23. 